\title{
ULTRASOUND ELASTOGRAPHY: REVIEW OF TECHNIQUES, CLINICAL APPLICATION, TECHNICAL LIMITATIONS, AND SAFETY CONSIDERATIONS IN NEONATOLOGY
}

\author{
SCHRENK $F^{1}$, UHRIK $\mathrm{P}^{2}$, UHRIKOVA $Z^{1}$ \\ ${ }^{1}$ Clinic of Neonatology, Jessenius Faculty of Medicine in Martin, Comenius University in Bratislava \\ and Martin University Hospital, Slovak Republic \\ ${ }^{2}$ Clinic of Internal Medicine - Gastroenterology, Jessenius Faculty of Medicine in Martin, \\ Comenius University in Bratislava and Martin University Hospital, Slovak Republic
}

\begin{abstract}
A b s tract
Ultrasound elastography is a relatively new non-invasive diagnostic imaging technology that maps elastic properties and the stiffness of soft tissue. In general, these methods can be classified into strain imaging methods that use internal or external compression stimuli and a shear wave imaging that use ultrasound-generated travelling shear wave stimuli. In this review we describe the basics of ultrasound elastography, discuss differences between various ultrasound elastography techniques, and review advantages, limitations, and the safety of these techniques in clinical practice, especially in neonatology. Furthermore, we review the potential of application of elastography in revealing brain injury and characterizing age dependent differences in preterm and term infants.
\end{abstract}

Key words: ultrasound, elastography, elasticity, shear wave, newborn

\section{INTRODUCTION}

Ultrasonography has been universally used for diagnostics since the 1970's (1). From that time ultrasonography has an essential part in diagnostics of neonatal neurologic injury, the assessment of intracerebral structural abnormalities, bleeding, ventriculomegaly or hydrocephalus, and periventricular leukomalacia (2). Transcranial Doppler ultrasonography provides information on the cerebral hemodynamics, brings a better visualization of blood vessels and the quantification of cerebral blood flow $(2,3)$. Moreover, ultrasonography provides an image in real-time and it is portable, so it can be brought to the bedside. Additionally, it is lower in cost than other imaging modalities and does not use harmful ionizing radiation (1).

So far various new ultrasound methods have been developed. One of these novel ultrasound modalities is elastography which enables to enlarge the diagnostic capacity of conventional ultrasound by evaluating elastic properties and the stiffness of soft tissue. The clinical application of elastography in adult populations began with separation of benign from malignant lesion in breast tissue but nowadays it is also used in common clinical practice for the evaluation of hepatic cirrhosis and fibrosis, the detection of prostate cancer, evaluation of thyroid nodules, etc. $(4,5)$.

In neonatology quantifiable measurements of tissue stiffness may have a unique role in diagnostics. Premature newborns are at a higher risk of serious neurologic injury and impaired neurodevelopment than term newborns. Those pathological processes related to a

Corresponding author: Zuzana Uhríkova, M.D. PhD.; e-mail: bukovinska.zuzana@gmail.com

(c) 2020 Zuzana Uhrikova et al.

This work is licensed under the Creative Commons Attribution-NonCommercial-NoDerivs 4.0 License (https://creativecommons.org/licenses/by-nc-nd/4.0/) 
preterm birth are mostly followed by changes in brain stiffness so their detection by ultrasound elastography can be useful in revealing brain injury and further characterizing age dependent differences in preterm and term infants $(6,7,8,9)$.

\section{ULTRASOUND ELASTOGRAPHY IN GENERAL}

Elastography assesses tissue elasticity which means the ability of solid tissue to acquire its original shape if the force stops applying (10). The elasticity of soft tissues is expressed by elastic moduli which are specific to the type of stress and the type of strain. These moduli are typically calculated using one of the elastography methods with respect to the directly measured quantity of tissue deformation. In general, these methods can be classified into "strain imaging" methods that use internal or external compression stimuli and "shear wave imaging" that use ultrasound-generated travelling shear wave stimuli (11).

\section{Strain elastography}

Strain elastography (SE) or quasi-static elastography (occasionally called just 'elastography') is one of the earliest elastography techniques. Tissue dimensionality alters due to applied pressure. This deformation is called a strain. Stiffer lesions deform less, therefore they have higher Young's modulus and lower strain $(12,13)$. SE estimates tissue stiffness due to tissue excitation stimuli. These stimuli include the excitation of tissue caused by manually applying pressure with the ultrasound transducer and the tissue excitation generated by the internal natural physiologic motion, such as cardiac pulsation and respiration, while the ultrasound transducer is held steady $(1,10,13)$.

The specific kind of excitation in SE is focused acoustic radiation force - "push pulses" followed by a tissue displacement. This method is named as an acoustic radiation force impulse imaging (ARFI imaging) and does not depend on transducer compression $(14,15)$. One transducer monitors the tissue displacement as well as generates push pulses. The tissue stiffness is inversely linked to the tissue displacement response that is directly related to the magnitude of the applied force. The benefit of this method is being able to focus the 'push' within deep lying organs, where the deformation with compression from the body surface is not possible or it is very difficult (11).

The results of this tissue excitation are automatically calculated strain values which are presented as an image known as a strain elastogram (14). Routinely, the strain elastogram is displayed as coloured pixels on red/blue or grey scale (16). Many users use to denote red colour as stiff (symbolizing a danger or an alarm) and blue as soft, whereas many others have chosen the opposite (blue correlates the stiff region, red the soft region) (15).

\section{Shear wave elastography}

Shear wave elastography (SWE) is based on the velocity monitoring of shear waves propagating in the tissue. A shear wave speed is high in stiff tissues and low in soft tissues, therefore the result of measurement of shear waves is the qualitative and quantitative estimation of the tissue elasticity. The shear wave speed image is usually presented as a colour overlay on a greyscale B-mode image with either red or blue denoting stiff tissues. A colour bar at the side of the image will relate the colours to either the shear wave speed or calculated Young's modulus. Since the image is quantitative the operator may place a cursor or define a region of interest (ROI) and obtain the average shear wave speed or Young's modulus estimate from that location (10).

Similar to SE, generated shear waves can be the result of variety of sources, such as physiologic motion, external vibration, and acoustic radiation force (11). In $1 D$ Transient Elastography (1D-TE) the probe applies regulated vibrating external "punches" on the surface of a body that generate shear waves propagating through the tissue. The same probe then calculates the shear wave speed as well as Young's modulus (18). Another modality based on the shear wave speed measurement is Point Shear Wave Elastography ( $p S W E$ ). This method works with ARFI, which causes tissue excitation with following monitoring of 
the shear wave propagation outside of the push location throughout an exact homogenous ROI (routinely $1 \mathrm{~cm}^{2}$ ). Contrary to ARFI used in SE, the tissue displacement itself is not measured (11). Unlike $1 D-T E, p S W E$ can use B-mode to visualize the tissue parenchyma (19).

The novel method in SWE is 2D Shear Wave Elastography (2D-SWE) which also uses ARFI to excite the tissue by a focused ultrasonic beam to multiple focusing zones simultaneously with a supersonic velocity (Super Sonic Imagine). This is allowing: the real-time monitoring of shear waves in 2D (in m/s), Young's modulus E computation (in kPA), and quantitative elastograms generating. $(20,21)$

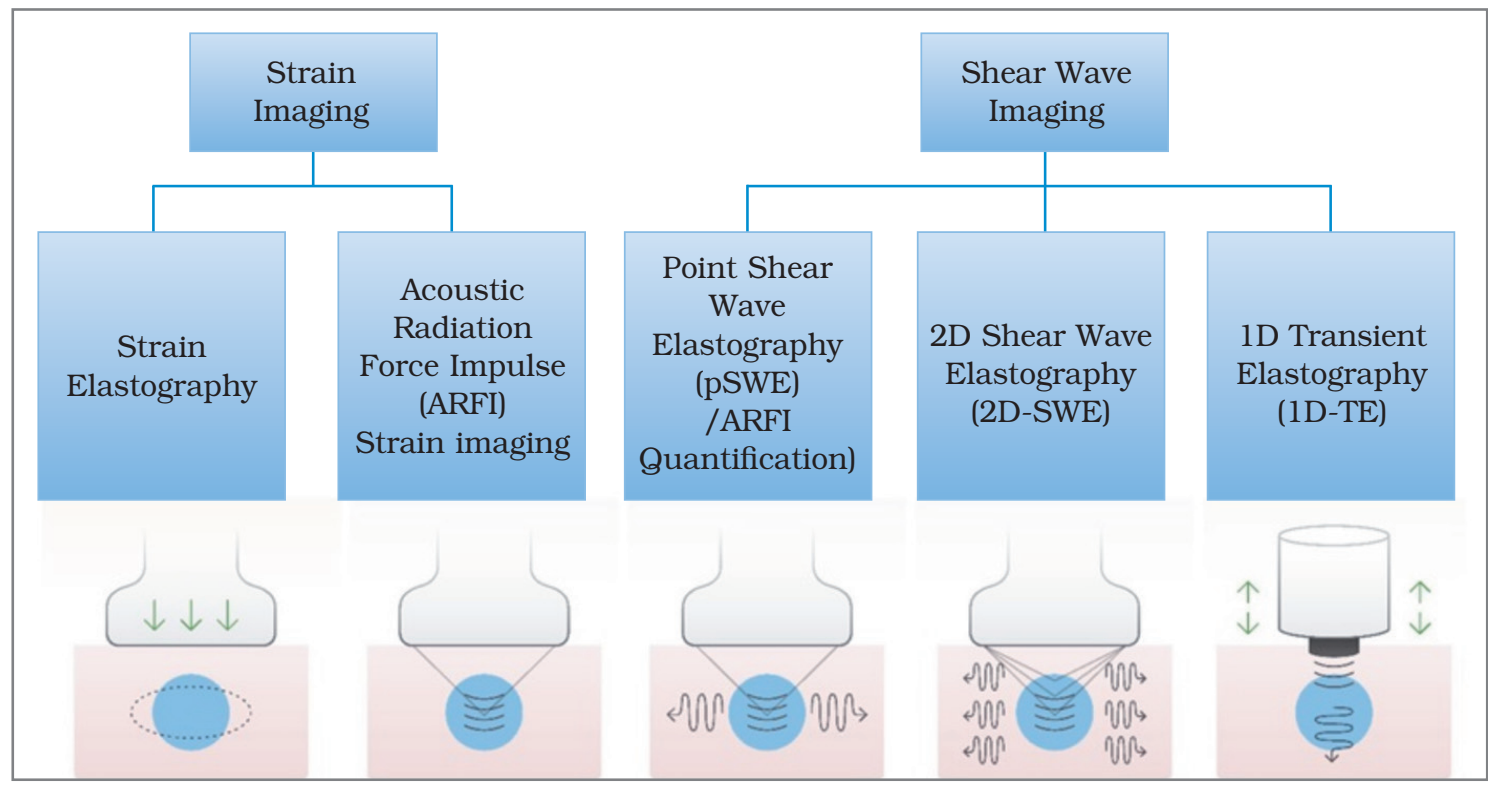

Fig. 1 Ultrasound elastography techniques with their excitations methods (10).

\section{CLINICAL APPLICATION IN NEONATOLOGY}

Crucial period of neurodevelopment represents the last trimester of gestation when various mechanisms taking place, including the beginning of myelination, neuronal organization, spinogenesis, and synaptogenesis followed by significant brain size growth and essential gyrification $(6,7,8)$. These well-organized and precisely scheduled development processes are vulnerable and very sensitive to insults related to preterm birth and they are associated with the changes in brain stiffness (9).

The assumptions that stiffness changes in neonatal brain present degree of myelination according to gestational age were also presented in a study published by Su et al. (2015). Their measurements of the elasticity of neonatal cerebral white and grey matters in a group of preterm and term infants with ARFI showed that stiffness across all regions was lower in preterm infants than in those born in term (22). The same conclusion that the degree of elasticity of a certain region changed according to the gestational age brought results obtained by using the SE by Kim et al. (2017) (23). Concordantly, Albayrak and Kasap (2018) presented results gained by using 2D-SWE in term as well as preterm neonates, where the stiffness values of thalamus and periventricular white matter were higher in term newborns. Their hypothesis was that changes in elasticity of neonatal brain are results not only caused by myelinization but also neuronal, glial proliferation, migration, and the organizational development of cortical layers and circuitry (24). Interestingly, El-Ali et al. (2019) 
had similar results but did not find differences in white matter stiffness based on gestational age as described in previous studies. The authors also admit that differences in chronological age of the child at imaging were different as in other studies, which could lead to this discrepancy (25).

In all of these studies different stiffness values depended on the anatomical locations as result of neurodevelopmental changes - the myelination in the brain goes from central to peripheral regions - from the brainstem to the thalamic and basal ganglia, and to the cortical hemispheres. In Su et al. study (2015) elasticity measurements in term newborns showed that stiffness increases from cerebral falx, cerebellum, thalamus, and basal ganglia to parietal white matter (22). Moreover, Albayrak and Kasap (2018) also found that periventricular white matter had higher elasticity than the subcortical white matter. That difference may be important finding as periventricular white matter is more vulnerable to periventricular leukomalacia in premature neonates (24). These results can be used to estimate the normal elasticity of the neonatal brain and may be useful in future as a prognostic factor of impaired neurodevelopmental outcome typically linked with prematurity, but more research is still needed.

Quantitative estimation of elasticity also objectifies ultrasound examination and shows potential in standard diagnostic of hypoxic - ischemic brain damage resulting in a clinically serious condition known as hypoxic- ischemic encephalopathy (HIE). HIE is the cause of neonatal death in 3-5 of 1,000 newborn infants, which is also presented by findings of various experimental studies $(26,39)$. In $\mathrm{Xu}$ et al. studies $(2013,2014)$ performed on animal models after occlusion of the middle cerebral artery (MCA) followed by reperfusion. SWE measurements showed a decrease of tissue stiffness on ipsilateral site to the site of injury over time and the contralateral site of injury increased in stiffness. According to the authors the decrease in stiffness on ipsilateral site was caused by liquefactive necrotic changes from hypoxic ischemia and oedema, on the other hand, the increase in elasticity on the contralateral site was due to a reduced regional blood flow in combination with elevated intracranial pressure created by a large volume of oedema formed in the ipsilateral hemisphere $(27,28)$. Similar findings also present Martin et al. (2012) in his study on an animal model of ischemic stroke (29).

A relatively extensive study also conducted on animal models with different findings was presented by Wang et al. (2015). A team of authors compared changes in elasticity of tissue after local ischemic as well as asphyxia brain damage. Each animal underwent ultrasound examination using ARFI preoperatively and postoperatively. In the group of induced ischemia there was a significant increase in tissue stiffness postoperatively. For asphyxia induced group all results were significantly higher than in preoperative measurements, as well as higher than in the ischemic group. The authors present these findings as the result of changes in cerebral hemodynamic especially in cerebral blood pressure and insufficient self-regulatory mechanisms typical for premature newborns. The authors also observed correlation with histopathological changes in brain tissue like presence of oedema of periventricular cells and changes in hierarchical structure worsening with the severity of condition (30).

Similar results were showed in a study published by Zhu et al. (2019. The studied animals were divided into 3 groups: mild asphyxia, moderate asphyxia and control group and examined with using ARFI. They found that shear wave velocities increased within 24-72 hours after the surgery in the moderate asphyxia group and within 48-72 hours after the surgery in the mild asphyxia group. Shear wave velocity changes coincided with histopathological changes in brain structure typical for hypoxic - ischemic brain injury, including neuronal demyelination, hyperplasia, and necrosis; oedema around vascular structures; and bleeding in the ependymal and periventricular areas. Those changes were obvious within 48 hours after the surgery in the mild asphyxia group and within 4 hours after the surgery in the moderate asphyxia group. The severity of these changes worsens over time and correlate with the results of shear wave velocities increasing. These findings suggest that brain 
damage following ischemia - hypoxia gradually worsens over time and this process can be seen as an increase in stiffness of brain tissue (31).

Thus, measurement of elasticity can detect early pathologic changes in the brain following hypoxia - ischemia injury. That brings us new possibilities for early clinical detection of pathological processes.

\section{TECHNICAL LIMITATIONS OF ULTRASOUND ELASTOGRAPHY}

With growing popularity of ultrasound elastography also the necessity to understand current technical limitations became more and more important. The same as the general ultrasound, several limiting factors are well- known, such as shadowing, reverberation, and clutter artefacts; or the operator-dependent nature of free hand ultrasound system (32). Ultrasound elastography methods, which depend on external stimuli like SE, are the most challenging to reproduce.

As the manual compression allowed using different amplitudes of the applied stress from one measurement to another, also from one examiner to another, the results can be distorted or inaccurate. Also the selection of the ROI is subjective and can affect variability of the results (33).

For neonatal ultrasonography the size of fontanels and the distance between the skull plates can be limiting factors for a proper performance of the brain structure examination as well as impossibility to directly cooperate with infants. Additionally, an important disadvantage is that available manufacturer's elastography a system from one to other use different settings and design and that is why measurements comparing are usually difficult $(20,32)$.

\section{SAFETY CONSIDERATIONS}

Elastography techniques are widely used and considered to be without any significant harmful risks for a clinical use (34). Accepted safety precautions are identical to those raised for general ultrasonography. The safeness of diagnostic ultrasonic imaging methods is monitored through several metrics, counting Thermal Index (TI) - associated with the tissue heating bio-effect and Mechanical Index (MI) - associated with the cavitation bio-effect (11).

Based on the currently published safety statements according to the World Federation for Ultrasound in Medicine and Biology (WFUMB), MI and TI values should be monitored continuously throughout the investigation and kept as low as possible. Moreover, the ALARA (As Low As Reasonably Achievable) principle should be followed. It means making every reasonable effort to maintain the exposures as far below the dose limits as practical. According to the British Medical Ultrasound Society (BMUS) the statements approved by WFUMB in postnatal diagnostics, TI values for bones $3.0-4.0$ should not exceed an investigation time of more than $1 \mathrm{~min}$., TI values for bones 4.0 - 5 should not exceed an investigation time of more than 15 seconds, while TI for bones values greater than 5 should not exceed 5 seconds in investigations. Significant risks in standard diagnostic ultrasonography in most tissues can occur at MI values > $1.9(35,36,37)$.

Despite the fact that the bioeffect of the acoustic radiation force has not been revealed to be harmful, radiation forces generated by ARFI pulses are longer than those associated with conventional B-mode/Doppler imaging. Because of that the ALARA principle should be followed and clinical studies about the impact of ARFI are needed to assess. Nowadays commercially available radiation force-based systems are designed to operate within the accepted diagnostic limits (11).

Unfortunately, the fact is that knowledge about the safety on the neonatal brain are limited and relevant studies are always missing. So far only one research was performed in animal model focused on the biological effect of elastography mechanism. In the study designed by Li et al. (2016) 24-hours old neonatal mice were exposed to SWE scanning for the duration of $10 \mathrm{~min}, 20 \mathrm{~min}$, and $30 \mathrm{~min}$ and compared with a sham group irradiated for 30 min with the transducer powered off. Mice from each group underwent a different analysis to explore the immediate and long-term impact of dynamic radiation force on the neonatal brain. The results 
showed that the histological specimens obtained 24 hours and 3 months after the scanning have no mechanical or thermal damage. Interesting finding was that the western blot analysis showed that the expression of proteins associated with neurite extension and synaptic plasticity in 24-hours old mice was changed to a control group. However, an additional measurement in 3-months old mice brought no difference in expression of these proteins between groups. It can be assumed that these pathway interferences were temporary. Besides of this no significant findings were detected in all parameters of MWM test (Morris water maze test) between the four groups. Although the study suggests that the pathway involvement was short term and can be self-repaired after some time, more attention should be given to scanning duration and more researches should be provided in this field (38).

\section{CONCLUSION}

Elastography is a non-invasive medical imaging technique that allows to determine the tissue stiffness of organs as one of the most remarkable indicator of pathological processes. These mechanical properties cannot be obtained by conventional ultrasound techniques. In recent years numerous methods have been developed to study the tissue elasticity for plenty applications (liver, thyroid, prostate, blood vessels, breasts, etc.) but also application in neonatology seems to be potentially useful in revealing brain injury or further characterizing age dependent differences in preterm and term infants. Despite its limitations, ultrasound elastography holds great clinical promise as measurements have shown outstanding correlation with diffuse and focal physiological or pathological processes in the neonatal brain.

Funding: This work was supported by Ministry of Health of the Slovak Republic under the project registration number 2019/44-UKMT-7.

\section{REFERENCES}

1. Shiina T, et al. WFUMB guidelines and recommendations for clinical use of ultrasound elastography: Part 1: basic principles and terminology. Ultrasound in medicine \& biology, 2015, 41.5: 1126-1147.

2. Decampo D, Hwang M. Characterizing the neonatal brain with ultrasound elastography. Pediatric neurology, 2018, 86: 19-26.

3. Gabriel M L, Piatto V B, Souza A S. Clinical application of transcranial Doppler ultrasonography in premature, very - low - birth - weight neonates. RadiolBras, 2010, 43.4: 213-8.

4. Sarvazyan A, et al. An overview of elastography - an emerging branch of medical imaging. Current Medical Imaging, 2011, 7.4: 255-282.

5. Zemanová M. Nová diagnostická zobrazovací metoda - Shear waves elastografie. Česká a Slovenská oftalmologie, 2016, 72.4: 103-110

6. Kostović I; Jovanov - Milošević N. The development of cerebral connections during the first 20-45 weeks' gestation. In: Seminars in Fetal and Neonatal Medicine. WB Saunders, 2006. p. 415-422.

7. Clouchoux $\mathrm{C}$, et al. Normative fetal brain growth by quantitative in vivo magnetic resonance imaging. American journal of obstetrics and gynecology, 2012, 206.2: 173. e1-173. e8.

8. Kostović I; Vasung L. Insights from in vitro fetal magnetic resonance imaging of cerebral development. In: Seminars in perinatology. WB Saunders, 2009. p. 220-233.

9. Bouyssi-Kobar M, et al. Third trimester brain growth in preterm infants compared with in utero healthy fetuses. Pediatrics, 2016, 138.5: e20161640.

10. Sigrist R, et al. Ultrasound Elastography: Review of Techniques and Clinical Applications. Theranostics [online].2017,7(5), 1303-1329 [cit. 2019-06-25]. DOI: 10.7150/thno.18650. ISSN 1838-7640.Dostupné z:http://www.thno.org/v07p1303.htm 
11. Gennisson, JL, et al. Ultrasound elastography: Principles and techniques. Diagnostic and Interventional Imaging [online].2013, 94(5), 487-495 [cit. 2019-06-25]. DOI: 10.1016/j.diii. 2013.01.022. ISSN 22115684.Dostupné z: https://linkinghub.elsevier.com/retrieve/pii/S22 11568413000302

12. Garra B S. Elastography: history, principles, and technique comparison. Abdominal imaging, 2015, 40.4: 680-697.

13. Itoh A, et al. Breast disease: clinical application of US elastography for diagnosis. Radiology, 2006, 239.2: 341-350.

14. Nightingale $\mathrm{K}$, et al. Acoustic radiation force impulse imaging: in vivo demonstration of clinical feasibility. Ultrasound in medicine \& biology, 2002, 28.2: 227-235.

15. Catheline S, et al. Diffraction field of a low frequency vibrator in soft tissues using transient elastography. IEEE transactions on ultrasonics, ferroelectrics, and frequency control, 1999, 46.4: 1013-1019.

16. Dietrich C F, et al. Strain elastography-how to do it?.Ultrasound international open, 2017, 3.04: E137-E149.

17. Sandrin L, et al. Shear elasticity probe for soft tissues with 1-D transient elastography. IEEE transactions on ultrasonics, ferroelectrics, and frequency control, 2002, 49.4: 436-446.

18. Tang A, et al. Ultrasound elastography and MR elastography for assessing liver fibrosis: part 1, principles and techniques. American journal of roentgenology, 2015, 205.1: 22-32.

19. Ferraioli G, et al. WFUMB guidelines and recommendations for clinical use of ultrasound elastography: Part 3: liver. Ultrasound in medicine \& biology, 2015, 41.5: 1161-1179.

20. Cosgrove D, et al. EFSUMB guidelines and recommendations on the clinical use of ultrasound elastography. Part 2: Clinical applications. Ultraschall in der Medizin-European Journal of Ultrasound, 2013, 34.03: 238-253.

21. Shankar H; Pagel P S. Potential Adverse Ultrasound-related Biological Effects A Critical Review. Anesthesiology: The Journal of the American Society of Anesthesiologists, 2011, 115.5: 1109-1124.

22. Su Y, et al. Evaluation of neonatal brain development using acoustic radiation force impulse imaging (ARFI). Neurophysiology, 2015, 47.4: 322-325.

23. Kim H G, et al. Ultrasound elastography of the neonatal brain: preliminary study. Journal of Ultrasound in Medicine, 2017, 36.7: 1313-1319.

24. Albayrak E; Kasap T. Evaluation of Neonatal Brain Parenchyma Using 2 Dimensional Shear Wave Elastography. Journal of Ultrasound in Medicine, 2018, 37.4: 959-967.

25. El-Ali A M, et al. Feasibility and reproducibility of shear wave elastography in pediatric cranial ultrasound. Pediatric Radiology, 2019, 1-7.

26. Yao D, et al. Establishment and identification of a hypoxia-ischemia brain damage model in neonatal rats. Biomedical reports, 2016, 4.4: 437-443.

27. $\mathrm{Xu} \mathrm{Z} \mathrm{S}$, et al. Evidence of changes in brain tissue stiffness after ischemic stroke derived from ultrasound based elastography. Journal of Ultrasound in Medicine, 2013, 32.3: 485-494.

28. Xu Z S, et al. Detection of mild traumatic brain injury in rodent models using shear wave elastography: preliminary studies. Journal of Ultrasound in Medicine, 2014, 33.10: 1763-1771.

29. Martin A, et al. Imaging of perfusion, angiogenesis, and tissue elasticity after stroke. Journal of Cerebral Blood Flow \& Metabolism, 2012, 32.8: 1496-1507.

30. Wang S-D, et al. Different extent of hypoxic-ischemic brain damage in newborn rats: histopathology, hemodynamic, virtual touch tissue quantification and neurobehavioral observation. International journal of clinical and experimental pathology,2015,8.10: 12177. 6

31. Zhu Z H, et al. Acoustic Radiation Force Impulse Imaging With Virtual Touch Tissue Quantification Enables Characterization of Mild Hypoxic Ischemic Brain Damage in Neonatal Rats. Journal of Ultrasound in Medicine, 2019, 38.7: 1797-1805.

32. Bamber J, et al. EFSUMB guidelines and recommendations on the clinical use of ultrasound elastography. Part 1: Basic principles and technology. Ultraschall in der Medizin-European Journal of Ultrasound, 2013, 34.02: 169-184.

33. Bercoff $\mathrm{J}$;Tanter M; Fink M. Supersonic shear imaging: a new techniquefor soft tissue elasticity mapping. IEEE transactions on ultrasonics, ferroelectrics, and frequency control, 2004, 51.4: 396-409. 
34. Ertl M, et al. Transtemporal investigation of brain parenchyma elasticity using 2-D shear wave elastography: Definition of age-matched normal values. Ultrasound in medicine\&biology, 2018, 44.1: 78-84.

35. WFUMB. WFUMB Clinical Safety Statement for Diagnostic Ultrasound - an overview. 2019.WFUMB Administrative Council. Retrieved from: https://wfumb.info/2019/04/15/echoes2-2-2-2-2-2-2-2-2-2-2-2-2-2-2-2-2-2-2-2-2-2/

36. BMUS. Guidelines for the safe use of diagnostic ultrasound equipment. 2010. The Safety Group of the British Medical Ultrasound Society, Ultrasound, 18,

37. Sedlár̆ M; Staffa E; Mornstein V. Zobrazovací metody využívající neionizující záření. 2013. Brno: Biofyzikální ústav Lékařské fakulty Masarykovy univerzity $\mathrm{v}$ Brně. Retrieved from: http://www.med.muni.cz/biofyz/zobrazovacimetody/files/zobrazovaci_metody.pdf.

38. Li C, et al. An experimental study of the potential biological effects associated with 2-D shear wave elastography on the neonatal brain. Ultrasound in medicine\&biology, 2016, 42.7: 1551-1559.

39. Gumulak R, et al. Cerebral near-infrared spectroscopy in term newborns: reference values and hypoxic-ischemic encephalopathy. Acta Medica Martiniana, 2019, 19.2: 58-63.

Received: April, 14, 2020

Accepted: May, 15, 2020 